\title{
Isolation and Partial Characterization of Three Classes of Mutant in Pseudomonas syringae Pathovar pisi with Altered Behaviour towards Their Host, Pisum sativum
}

\author{
By AFSHAN N. MALIK, ${ }^{1} \dagger$ ALAN VIVIAN ${ }^{*} \ddagger$ AND \\ JOHN D. TAYLOR ${ }^{2}$ \\ ${ }^{1}$ School of Biological Sciences and Environmental Health, Thames Polytechnic, \\ Wellington Street, London SE18 6PF, UK \\ ${ }^{2}$ Institute of Horticultural Research, Wellesbourne, Warwick CV35 9EF, UK
}

(Received 2 April 1987; revised 6 May 1987)

\begin{abstract}
Mating with Escherichia coli strain SM10 carrying the Tn5 vector pSUP2011 was used to mutagenize Pseudomonas syringae pv. pisi strain 299A. The resulting transconjugants were each tested by stem-inoculation into several pea (Pisum sativum) cultivars. Three classes of mutant, which probably resulted from insertion of part or all of RP4-2-Tc::Mu into the genome of strain $299 \mathrm{~A}$, showed reduced virulence towards one or more pea cultivars. The single class I mutant was avirulent on all pea cultivars tested and had lost the ability to induce a hypersensitive response in tobacco (Nicotiana tabacum) cv. White Burley; the single class II mutant induced a hypersensitive response on all pea cultivars and tobacco; class III mutants showed reduced virulence towards pea cv. Early Onward, while remaining fully virulent towards other normally susceptible pea cultivars, and inducing a hypersensitive response in tobacco.
\end{abstract}

\section{INTRODUCTION}

Pseudomonas syringae pv. pisi causes bacterial blight of peas (Pisum sativum) (Lawyer, 1984). In common with some other plant-pathogenic pseudomonads, this organism exhibits a welldefined race structure and strains can be distinguished on the basis of differential interaction with a range of host cultivars (Taylor, 1986). The interactions of host and pathogen are essentially of two kinds: compatible and incompatible. A compatible interaction results in the establishment of the pathogen and development of disease symptoms in the host. An incompatible interaction results in the induction of host defences leading to the development of a hypersensitive response (HR) in the host. HR limits the development of the pathogen and results in a localized necrotic lesion close to the site of infection (Klement, 1963). HR also develops when plant-pathogenic bacteria are introduced into the leaves of a non-host plant such as tobacco (Nicotiana tabacum).

In an attempt to investigate genes involved in pathogenicity we have used the transposon vector pSUP2011 (Simon et al., 1983) to mutagenize the race 1 strain, 299A, of $P$. syringae pv. pisi. A rapid stem-inoculation technique permits screening of mutagenized transconjugants against a range of pea cultivars. This paper describes the isolation and initial characterization of three classes of mutant affected in their ability to cause disease in one or more pea cultivars.

† Present address: Department of Haematology and Oncology, Institute of Child Health, 30 Guilford Street, London WCIN IEH, UK. U⿳亠丷厂犬.

$\ddagger$ Present address: Science Department, Bristol Polytechnic, Coldharbour Lane, Frenchay, Bristol BS16 1QY,

Abbreviation: HR, hypersensitive response.

0001-4120 (C) 1987 SGM 
Strain no.

\section{Table 1. Bacterial strains and plasmids}

\section{Relevant properties}

P. syringae pv. pisi
299A
PF21
PF22-25
PF26-27
PF28
PF32
PF35
PF49-91
PF92-108, 110-
PF109, 124
PF201
Escherichia coli
J-53
SM10
Plasmids
RP4
RP4-2-Tc:: Mu
RP4-4
pSUP2011
pKAN2

Race 1, wild type; derivatives prefixed PF

Path ${ }^{-}$class I $\left(\mathrm{Km}^{\mathrm{s}}\right)$

Path- class III $\left(\mathrm{Km}^{\mathrm{s}}\right)$

Path- class III $\left(\mathrm{Km}^{\mathrm{r}}\right)$

Path ${ }^{-}$class I $\left(\mathrm{Km}^{\mathrm{s}}\right)$

Path- class II $\left(\mathrm{Km}^{\mathrm{s}}\right)$

Path- class II $\left(\mathrm{Km}^{\mathrm{r}}\right)$

Path- class III $\left(\mathrm{Km}^{\mathrm{r}}\right)$; HR on cv. Early Onward

Path ${ }^{-}$class III $\left(\mathrm{Km}^{\mathrm{r}}\right)$; reduced virulence on

cv. Early Onward

Path- class III $\left(\mathrm{Km}^{r} \mathrm{Sm}^{r} \mathrm{Tn} 5\right)$; reduced virulence on cv. Early Onward

Wild type, RP4-4

Pro $^{-} \mathrm{Met}^{-}$

$\mathrm{Thr}^{-} \mathrm{Leu}^{-} \mathrm{Thi}^{-}$

RP4-2-Tc : : Mu in chromosome

$\mathrm{Ap}^{r} \mathrm{Km}^{r} \mathrm{Tc}^{r}$
$\mathrm{Km}^{r} \mathrm{Tra}^{+}\left(\mathrm{Ap}^{\mathrm{s}}\right.$ due to ISR $I$ in $\mathrm{Tn} l$ )
$\mathrm{Km}^{\mathrm{s}}$ derivative of RP4 $^{\mathrm{A}} \mathrm{Ap}^{r} \mathrm{Km}^{r} \mathrm{Cm}^{r} \mathrm{Tn} 5$ (pBR325 replicon)
Internal HindIII fragment of Tn5 cloned in pBR322 (used
as probe for Tn5)
Reference/source

Taylor $(1972 b)$
299A
299A
299A
PF21
PF35
299A
299A
299A
299A
299A $\times$ J53(RP4-4)
Clowes \& Hayes (1968)
Simon et al. (1983)

Datta et al. (1971)

Simon et al. (1983)

Hedges \& Jacob (1974)

Simon et al. (1983)

M. J. Daniels,

John Innes Institute

\section{METHODS}

Bacterial strains and plasmids. Strains of $P$. syringae pv. pisi and Escherichia coli, and plasmids, are listed in Table 1.

Confirmation of the identity of $P$. syringae pv. pisi isolates. Tests to confirm the identity of mutants which had lost pathogenicity involved the detection of a heat-stable antigen specific for $P$. syringae pv. pisi and were done as described previously (Taylor, 1972a; Taylor \& Dye, 1972).

Growth conditions. Strains of $P$. syringae pv. pisi were grown at $25^{\circ} \mathrm{C}$ in nutrient broth (NB, Oxoid no. 1) or on nutrient glycerol agar (NGA, Garrett et al., 1966) containing, $\mathrm{g}^{-1}: \mathrm{NB}, 8$; glycerol, 20 ; Difco Bacto agar, 20; Ltryptophan, $0.05 ; \mathrm{L}$-methionine, 0.05 . Strains of $E$. coli were grown at $37^{\circ} \mathrm{C}$ in Luria broth (LB) containing, $\mathrm{g} \mathrm{l}^{-1}$ : Difco Bacto tryptone, 15; Difco Bacto yeast extract, 5 ; NaCl, 5. Minimal medium (MSM) for both organisms was the minimal salts medium of Clowes \& Hayes (1968). Glucose was added to MSM as a sterile solution $(50 \%$, w/v) to give a final concentration of $0.5 \%(\mathrm{w} / \mathrm{v})$ immediately prior to use. Stock solutions of amino acids $\left(10 \mathrm{~g} \mathrm{l}^{-1}\right)$ and vitamins $\left(0 \cdot 2 \mathrm{~g} \mathrm{l}^{-1}\right)$ were separately sterilized and added to MSM as required to give final concentrations of 50 and $1 \mu \mathrm{g} \mathrm{ml}^{-1}$, respectively. Antibiotics, freshly prepared as solutions in sterile water, were added to MSM at the following final concentrations $\left(\mu \mathrm{g} \mathrm{m}^{-1}\right)$ : kanamycin sulphate, 50; dihydrostreptomycin sulphate, 1000 ; chloramphenicol (dissolved in $0 \cdot 1$ vol. ethanol and diluted in water, $80 \mathrm{mg} \mathrm{ml}^{-1}$ ), 40 ; ampicillin, 50 .

Use of phage PRDI. The pilus-specific phage PRD1 (Olsen et al., 1974) was used to detect cells harbouring Inc $P$ group plasmids. A lysate $(10 \mu \mathrm{l})$ of PRD1 $\left(10^{9}\right.$ p.f.u. $\left.\mathrm{ml}^{-1}\right)$ was spotted on a freshly inoculated NB culture $(16 \mathrm{~h})$ streaked on an NGA plate. After $24 \mathrm{~h}$ incubation, sensitivity was detected by interruption of the line of growth.

Filter-matings. A procedure similar to that of Towner \& Vivian (1976) was used. Equal volumes of NB or LB cultures $(16 \mathrm{~h})$ were mixed and passed through a Millipore filter ( $25 \mathrm{~mm}$ diam.; $0.45 \mu \mathrm{m}$ pore size), which was incubated $\left(24 \mathrm{~h}, 25^{\circ} \mathrm{C}\right)$ on the surface of an NGA plate. Growth on the filter was resuspended in quarter-strength Ringer's solution $(3 \mathrm{ml})$ and suitable dilutions were plated on selective media. For matings involving $E$. coli strain SM10(pSUP2011) and P. syringae pv. pisi strain 299A, the plasmid transconjugants were selected on MSM plus kanamycin.

Southern transfer and hybridization. Colony hybridization was done as described by Grunstein \& Hogness (1975). Filters were hybridized to nick-translated probes (Rigby et al., 1977), labelled to $10^{6} \mathrm{c.p} . \mathrm{m}$. per ml of hybridization solution containing $50 \%(\mathrm{v} / \mathrm{v})$ formamide, $2 \times \mathrm{SSC}\left(24 \mathrm{~h}, 42^{\circ} \mathrm{C}\right)(1 \times \mathrm{SSC}$ is $0.15 \mathrm{M}-\mathrm{NaCl}, 0.015 \mathrm{M}$-trisodium citrate, $\mathrm{pH} 7)$. Filters were washed once $\left(30 \mathrm{~min}, 60^{\circ} \mathrm{C}\right)$ in $0.1 \%(\mathrm{w} / \mathrm{v})$ SDS in $2 \times \mathrm{SSC}$ prior to autoradiography using Kodak X-OMAT X-ray film at $-70^{\circ} \mathrm{C}$ with intensifying screens (Cronex Lighting Plus).

Pathogenicity testing. A stem-inoculation procedure was used to test strains of $P$. syringae pv. pisi with pea cultivars grown (10-14 d) in $3 \cdot 2 \mathrm{~cm}$ peat blocks. Bacteria cultured $(16 \mathrm{~h})$ as patches on an NGA plate were scraped 

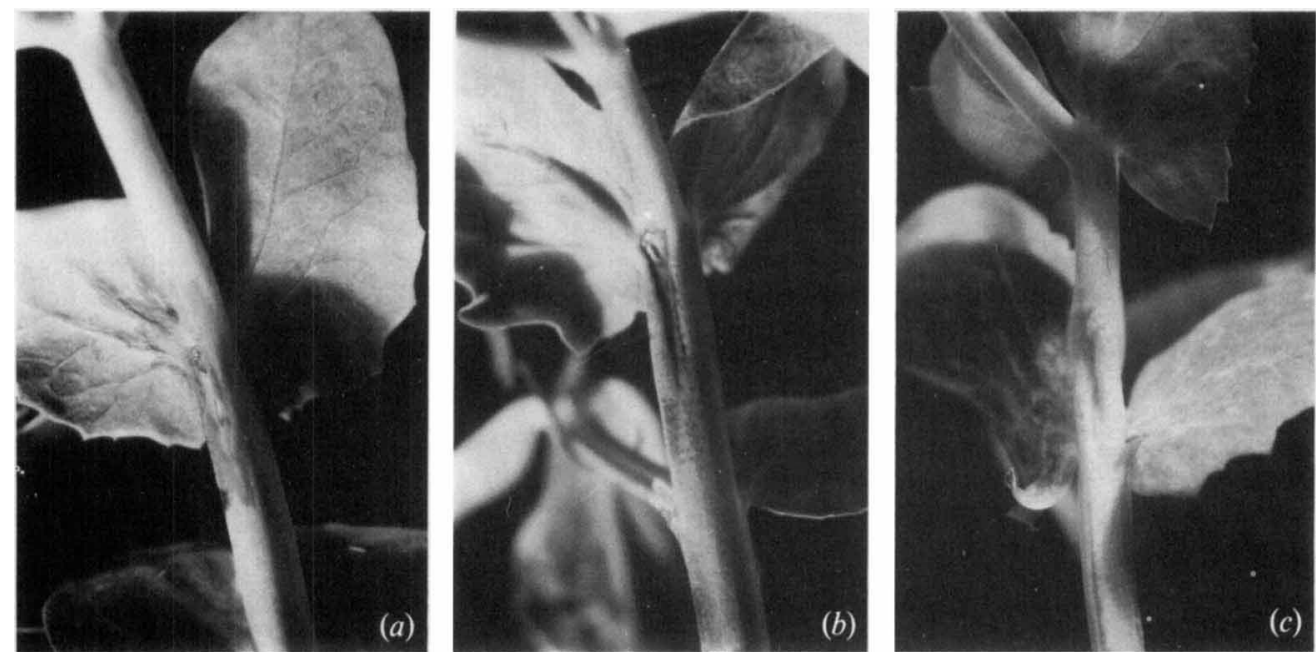

Fig. 1. Inoculation of pea seedlings. $P$. syringae pv. pisi stem-inoculated (see Methods) into seedlings $(10 \mathrm{~d})$ of pea and recorded after $7 \mathrm{~d}$ further growth. (a) Strain $299 \mathrm{~A}$ on cv. Kelvedon Wonder: compatible interaction; a typical water-soaked lesion spreading from the site of inoculation can be seen. (b) Strain PF22 on cv. Early Onward: incompatible interaction; a typical localized, necrotic lesion can be seen at the site of inoculation. (c) Strain PF21 on cv. Kelvedon Wonder: a null interaction; only the wound made by the inoculation is visible.

from the surface with a sterile entomologist's mounting pin and stabbed into the main stem at its junction with the stipules at the youngest two nodes (two inoculations per plant). The plants were maintained for 5-10 d before recording the results. A compatible (pathogenic) response typically showed an area of water-soaking spreading from the site of inoculation (Fig. 1a), whereas an incompatible response resulted in necrosis localized at the point of inoculation (Fig. $1 b$ ). Some mutants and $E$. coli showed a null response (Fig. $1 c$ ) in which no symptoms other than the inoculation wound were visible. Mutants that were reduced in their pathogenicity were identified by reduction of the area of water-soaking, together with the presence of visible necrosis.

Testing for hypersensitivity. Bacterial cultures were tested for HR by inoculation of Nicotiana tabacum $\mathrm{cv}$. White Burley (Klement, 1963).

Plasmid detection. The single-colony lysate technique (Eckhardt, 1978) was used to examine the plasmid content of $P$. syringae pv. pisi strains.

\section{RESULTS}

Use of the transposon vector pSUP2011

Transposon Tn 5 was chosen for attempted mutagensis of $P$. syringae pv. pisi. Preliminary experiments indicated that pSUP2011, one of a series of Tn 5 vectors developed by Simon et al. (1983), gave high frequencies (up to $10^{-1}$ per recipient) of inheritance of kanamycin resistance $\left(\mathrm{Km}^{\mathrm{r}}\right)$ with efficient 'suicide' of the delivery vector as shown by the failure to inherit chloramphenicol resistance or detect a plasmid of similar size to pSUP2011 in the recipients. The $E$. coli host carrying pSUP2011 has a derivative of the IncP group plasmid RP4 integrated into its chromosome. The RP4 derivative has a deletion in $\mathrm{Tn} l$ and an insertion of phage $\mathrm{Mu}$ in the tetracycline-resistance gene, so that only $\mathrm{Km}^{r}$ is expressed. The plasmid pSUP2011 has narrow-host-range replication functions and chloramphenicol resistance derived from pBR325, but can be mobilized by the chromosomal RP4 derivative because it carries the mobilization (Mob) region from RP4. Once transferred to hosts such as $P$. syringae pv. pisi, pSUP2011 is unable to replicate and is not maintained, although transposition of $\operatorname{Tn} 5$ may occur.

\section{Selection of mutants showing altered pathogenicity}

The $P$. syringae pv. pisi race 1 strain 299 A was filter-mated with $E$. coli strain SM10(pSUP2011) and approximately $500 \mathrm{Km}^{\mathrm{r}}$ transconjugants were isolated. Each was stem- 
Table 2. Interaction of $P$. syringae pv. pisi mutants with plants

Plant inoculation tests were performed as described in Methods. All strains were confirmed as $P$. syringae pv. pisi on the basis of serological tests (see Methods).

\begin{tabular}{|c|c|c|c|c|c|}
\hline \multirow[b]{2}{*}{$\begin{array}{l}\text { Class of } \\
\text { mutant }\end{array}$} & \multirow[b]{2}{*}{ Strain no. } & \multicolumn{3}{|c|}{ Interaction* with: } & \multirow[b]{2}{*}{$\begin{array}{l}\text { Approx. } \\
\text { frequency of } \\
\text { isolation }\end{array}$} \\
\hline & & $\begin{array}{c}\text { Pea } \\
\text { cv. Kelvedon } \\
\text { Wonder }\end{array}$ & $\begin{array}{c}\text { Pea } \\
\text { cv. Early } \\
\text { Onward }\end{array}$ & $\begin{array}{c}\text { Tobacco } \\
\text { cv. White } \\
\text { Burley }\end{array}$ & \\
\hline I & PF21 & $\mathrm{n}$ & $\mathrm{n}$ & $\mathrm{n}$ & $1 / 500$ \\
\hline II & PF35 & - & - & - & $1 / 500$ \\
\hline \multirow[t]{2}{*}{ III } & PF22-27, PF49-91 & + & - & - & $49 / 500$ \\
\hline & PF92-124 & + & $+1-$ & - & $33 / 500$ \\
\hline Wild-type & $299 \mathrm{~A}$ & + & + & - & $500 / 500$ \\
\hline
\end{tabular}

inoculated on pea cvs. Kelvedon Wonder and Early Onward, both of which are susceptible to the wild-type, 299A. All potential mutants showing reduction or loss of virulence towards either cultivar were tested on two further occasions. Three classes of mutant were identified and were also used to infect tobacco (Table 2).

A single class I mutant, designated PF21, showed a null response (Fig. 1c) on both the cultivars tested and also failed to elicit $\mathrm{HR}$ on tobacco. A spontaneous $\mathrm{Km}^{\mathrm{s}}$ derivative of PF21, designated PF28, retained the non-pathogenic phenotype of PF21. Both PF21 and PF28 were confirmed as $P$. syringae pv. pisi on the basis of serological tests. In addition, both strains harboured the plasmids pAV213 $(50 \mathrm{~kb})$ and pAV212 $(54 \mathrm{~kb})$ which were present in the wildtype strain 299A (Malik, 1985).

A single class II mutant, designated PF35, produced a typical incompatible response on both cv. Kelvedon Wonder and cv. Early Onward, and retained its ability to induce HR in tobacco. A spontaneous $\mathrm{Km}^{\mathrm{s}}$ derivative of PF35, designated PF25, maintained the class II phenotype on both pea cultivars, and also induced HR in tobacco. Both PF35 and PF25 were shown to be $P$. syringae pv. pisi on the basis of serological tests and harboured pAV213 and pAV212.

Class III mutants showed the normal compatible response with cv. Kelvedon Wonder but showed loss or reduction of virulence on cv. Early Onward. This class of mutants arose at high frequency, being represented by some $82 / 500$ transconjugants tested. The interaction with cv. Early Onward varied but was reproducible for a given isolate. Several class III mutants gave rise to spontaneous $\mathrm{Km}^{\mathrm{s}}$ variants, but this did not affect their phenotype towards pea.

About $40 \%$ of the class III mutants had undergone detectable changes in their plasmid content. These included apparent loss of either pAV213 or pAV212 or the acquisition of a larger plasmid accompanied by loss of one of the two plasmids normally present in strain 299A. No strains which had lost both pAV213 and pAV212 were detected and all remaining class III mutants showed no apparent change of plasmid profile.

\section{The genetic basis of the mutants}

The results described in the previous section cast doubt upon the role of $\mathrm{Tn} 5$ in the generation of the mutants, since frequently the loss of $\mathrm{Km}^{\mathrm{r}}$ was not accompanied by reversion of the mutant. It was therefore of some importance to determine whether Tn 5 were present in the mutants, and also, since RP4 could also confer $\mathrm{Km}^{\mathrm{r}}$, whether some or all of this plasmid were present. Colonies lysed on filters were probed with radiolabelled pKAN2 (Table 1) to detect Tn5 and RP4 to detect RP4-2-Tc:: Mu from strain SM10 (Table 1). Only two mutants, PF109 and PF124, showed strong hybridization with pKAN2: both also expressed high-level $\left(1000 \mu \mathrm{g} \mathrm{ml}^{-1}\right)$ resistance to streptomycin (see below), which is specified by $\mathrm{Tn} 5$. The remainder showed only weak hybridization to pKAN2 and were sensitive to streptomycin.

All of the mutants, including the $\mathrm{Km}^{\mathrm{s}}$ variants described above, hybridized strongly with RP4. There was weak hybridization between pKAN2 and RP4. Further, all of the mutants and 
Table 3. Inheritance of RP4 and RP4-4 in strain 299A and pathogenicity mutants

Filter matings were performed as described in Methods. Strains are listed in Table 1.

$\begin{array}{cccc}\text { Donor } & \text { Recipient } & \begin{array}{c}\text { Selected } \\ \text { resistance* }\end{array} & \begin{array}{c}\text { Frequency of plasmid } \\ \text { inheritance per recipient }\end{array} \\ \text { J5-3(RP4) } & \text { 299A } & \text { Tc } & 7.5 \times 10^{-1} \\ & & \mathrm{Km} & 1.0 \times 10^{-1} \\ \text { J5-3(RP4) } & \text { PF201 } & \mathrm{Km} & 6.9 \times 10^{-4} \\ \text { J5-3(RP4) } & \text { PF21 } & \text { Tc } & 1.2 \times 10^{-1} \\ \text { J5-3(RP4) } & \text { PF35 } & \text { Tc } & 6.9 \times 10^{-1}\end{array}$

* Km, kanamycin resistance; Tc, tetracycline resistance.

the $\mathrm{Km}^{\mathrm{s}}$ variants were sensitive to lysis by the IncP group pilus-specific phage, PRD1. The wildtype 299A was resistant to PRD1. These results suggest that the mutants harbour at least part of RP4-2-Tc: : Mu, inherited from strain SM10, and that loss of $\mathrm{Km}^{\mathrm{r}}$ was not accompanied by loss of the entire RP4-derivative sequences. Transconjugants of $P$. syringae pv. pisi strain 299A carrying RP4 were fully virulent on cv. Early Onward, indicating that the presence of this replicon was not responsible for the class III phenotype.

Examination of the plasmid content of the mutants failed to show the presence of additional plasmid bands, suggesting that RP4-2-Tc:: Mu or part of it had integrated into the $P$. syringae pv. pisi chromosome. Using a $\mathrm{Km}^{\mathrm{s}}$ derivative of RP4, designated RP4-4 (Hedges \& Jacob, 1974), it was possible to demonstrate a 100- to 1000 -fold reduction in inheritance of RP4 in a strain (PF201) harbouring an autonomous RP4-4 (Table 3). However, the mutants PF21 and PF35 did not show any reduction in the frequency of inheritance of RP4 (Table 3), indicating that an autonomous RP4 replicon was not present.

Tn5 expresses high-level resistance to streptomycin in $P$. syringae p $v$. pisi

The demonstration that mutants PF109 and PF124 harboured Tn5 and exhibited high-level resistance to streptomycin was used to determine the relative frequencies of Tn5 and RP4 inheritance in $P$. syringae pv. pisi from $E$. coli SM10(pSUP2011). In matings with strain 299A, Tn5 (streptomycin resistance) was inherited at $10^{-4}$, while $\mathrm{RP} 4\left(\mathrm{Km}^{\mathrm{r}}\right)$ was inherited at $10^{-1}$. This further supports the conclusion that part or all of the integrated RP4 present in SM10 is efficiently transferred to recipient strains in this case.

\section{DISCUSSION}

The observation that $\mathrm{Tn} 5$ expresses high-level streptomycin resistance in $P$. syringae pv. pisi permits selection with that antibiotic in preference to kanamycin. We have noted that it is extremely difficult to purify $P$. syringae pv. pisi transconjugants from $E$. coli in matings. However, use of streptomycin-resistant recipients or selection of Tn5 with streptomycin completely prevented growth of the $E$. coli donor. The expression of the streptomycin-resistance determinant on $\operatorname{Tn} 5$ has been reported for several other bacteria, including Rhizobium meliloti (Putnoky et al., 1983; Selveraj \& Iyer, 1984), Pseudomonas putida and Acinetobacter calcoaceticus (O'Neill et al., 1984).

Three classes of mutant were isolated which showed loss or reduction of virulence towards one or more cultivars of pea. The class I mutant, PF21, exhibited a null reaction with all pea cultivars tested and failed to produce HR in tobacco. The class II mutant, PF35, resembled the class I mutant but retained the ability to induce HR in pea and tobacco. Mutants of similar phenotype to classes I and II were isolated in P. syringae pv. phaseolicola by Panopoulos et al. (1984). Class III mutants were obtained at a much higher frequency than the other two classes and were unique in showing loss or reduction of virulence towards a single cultivar (Early Onward) of pea. Anderson \& Mills (1985) reported the isolation of several mutants of $P$. syringae pvs. syringae and phaseolicola which showed reduced virulence towards Phaseolus lunatus cv. PI 199791 and 
Phaseolus vulgaris $\mathrm{cv}$. Red Mexican respectively. These were induced after conjugation with $E$. coli SM10(pSUP1011) and were apparently due to Tn 5 insertion into the genes involved.

The precise cause of the mutations obtained with pSUP2011 remains in doubt. It has been observed in $E$. coli that when RP4 is integrated into the bacterial chromosome it no longer exhibits incompatibility towards autonomous RP4 derivatives present in the same cell (Watson $\&$ Scaife, 1980; Grinter, 1984). A clear demonstration of surface exclusion by $P$. syringae pv. pisi harbouring an autonomous RP4 towards the inheritance of RP4-4 here, but an absence of exclusion in the two mutants tested may further support the notion that RP4-2-Tc::Mu has integrated in these mutants. Turner et al. (1984) reported the anomalous behaviour of the closely related pSUP1011 in Xanthomonas campestris pv. campestris. These workers demonstrated that the RP4 derivative in the chromosome of $E$. coli SM10 had excised and transferred to the recipient $X$. campestris pv. campestris, thus introducing RP4 sequences and, potentially, phage $\mathrm{Mu}$ into the recipient genome. Clearly a similar situation pertains to the mutants isolated here. Integration of either RP4 or Mu into the recipient genome could cause mutations, in addition to the induction of mutants by $\operatorname{Tn} 5$ transposition. The balance of evidence presented here suggests that the phenotypes observed are probably due to integration of at least part of RP4 derived from strain SM10, although their precise basis must await further molecular analysis.

Whatever their basis, these mutants exhibited stable, (except for PF35), well-defined phenotypes in relation to the pea host. The class I mutant showed loss of both virulence towards pea and the ability to induce HR in pea and tobacco. Saprophytic bacteria are unable to induce HR, suggesting that this ability is in some way associated with the role of the pathogen in causing disease. However, Azad \& Kado (1984) obtained mutants of Erwinia rubrifaciens which were unable to induce $H R$ in tobacco, but remained pathogenic toward Harley walnut trees. The class II mutant, PF35, was unstable and spontaneous reversion to weak virulence was observed in some isolates.

The reason for the relatively frequent isolation of class III mutants is not known. Clearly the gene or genes responsible may be a preferred site for integration of RP4 or Mu. Approximately $40 \%$ of these mutants showed changes in their plasmid profile compared with that of strain $299 \mathrm{~A}$. It is not clear whether this represents plasmid involvement in the phenotype of the class III mutants. There is an indication that this class of mutants may be heterogeneous in nature, perhaps resulting from slight disturbances in a number of genes involved in pathogenicity, but to which cv. Early Onward is particularly sensitive.

This is the first report of a class of mutant showing loss of virulence towards a specific host cultivar. A commonly held interpretation of the gene-for-gene hypothesis (Flor, 1956) would predict that a mutation involving loss of function should be a mutation from avirulence to virulence, since specificity is considered to reside in the incompatible interaction between host and pathogen (Ellingboe, 1981; Crute \& Norwood, 1986). It is difficult to see how insertion of DNA at random into a gene could activate its expression, but if there were a preferred site for integration of DNA in these mutants, it might result in the insertion of a strong promoter close to a gene or genes responsible for avirulence which are otherwise inoperative toward cv. Early Onward.

A. N.M. is grateful for the award of an SERC studentship. We thank Dr C. M. E. Garrett for helpful discussions during the course of this work. We thank Lynne Craven, Veronica Grover and Sarah Reader for excellent technical assistance. The work was carried out under MAFF licences numbers PHF 31/161 and PHF 428A/42(96) issued under the Plant Pests (Great Britain) Order 1980.

\section{REFERENCES}

Anderson, D. M. \& Mills, D. (1985). The use of transposon mutagenesis in the isolation of nutritional and virulence mutants in two pathovars of Pseudomonas syringae. Phytopathology 75, 104-108.

AZAD, H. R. \& KADO, C. I. (1984). Relation of tobacco hypersensitivity to pathogenicity of Erwinia rubrifaciens. Phytopathology 74, 61-64.
Clowes, R. C. \& HaYes, W. (1968). Experiments in Microbial Genetics. Oxford \& Edinburgh: Blackwell Scientific Publications.

Crute, I. R. \& Norwood, J. M. (1986). Gene-dosage effects on the relationship between Bremia lactucae (downy mildew) and Lactuca sativa (lettuce): the relevance to a mechanistic understanding of host- 
parasite specificity. Physiological and Molecular Plant Pathology 29, 133-145.

Datta, N., Hedges, R. W., Shaw, E. J., Sykes, R. B. \& Richmond, M. H. (1971). Properties of an R factor from Pseudomonas aeruginosa. Journal of Bacteriology 108, 1244-1249.

ECKHARDT, T. (1978). A rapid method for the identification of plasmid DNA in bacteria. Plasmid 1, 584-588.

EllingboE, A. H. (1981). Changing concepts in hostpathogen genetics. Annual Review of Phytopathology 19, 125-143.

FloR, H. H. (1956). The complementary genetic systems in flax and flax rust. Advances in Genetics 8 , 29-54.

Garrett, C. M. E., Panagopoulos, C. G. \& Crosse, J. E. (1966). Comparison of plant pathogenic pseudomonads from fruit trees. Journal of Applied Bacteriology 29, 342-356.

GrINTER, N. J. (1984). Replication control of IncP plasmids. Plasmid 11, 74-81.

Grunstein, M. \& Hogness, D. S. (1975). Colony hybridisation: a method for the isolation of cloned DNAs that contain a specific gene. Proceedings of the National Academy of Sciences of the United States of America 72, 3961-3965.

HEDGES, R. W. \& JACOB, A. E. (1974). Transposition of ampicillin resistance from RP4 to other replicons. Molecular and General Genetics 132, 31-40.

KLEMENT, Z. (1963). Rapid detection of pathogenicity of phytopathogenic pseudomonads. Nature, London 199, 299-300.

LAWYER, A. S. (1984). Diseases caused by bacteria. In Compendium of Pea Diseases, pp. 8-11. Edited by D. J. Hagedorn. St Paul, Minnesota, USA: American Phytopathological Society.

MALIK, A. N. (1985). Genetic studies with Pseudomonas syringae pathovar pisi. $\mathrm{PhD}$ thesis, CNAA Thames Polytechnic.

Olsen, R. H., Siak, J. S. \& Gray, R. H. (1974). Characterisation of PRD1, a plasmid dependent broad host range DNA bacteriophage. Journal of Virology 14, 689-699.

O'Neill, E. A., Kiely, G. M. \& Bender, R. A. (1984). Transposon $\operatorname{Tn} 5$ encodes streptomycin resistance in nonenteric bacteria. Journal of Bacteriology 159, 388-389.

Panopoulos, N. J., Willis, D. K., Lindgren, P.,
Peet, R., Thom, R. F., Hickman, M. J. \& Orser, C. S. (1984). Gene analysis in two Pseudomonas syringae pathovars. In Proceedings of the 2nd Working Group on Pseudomonas syringae Pathovars, pp. 85-89. Edited by C. G. Panagopoulos, P. G. Psallidas \& A. S. Alivizatos. Athens: Hellenic Phytopathological Society.

Putnoky, B., Kiss, G. B., OTt, I. \& Kondorosi, A. (1983). Tn5 carries a streptomycin resistance determinant downstream from the kanamycin resistance gene. Molecular and General Genetics 191, 288-294.

Rigby, P. W. J., DieckmanN, M., Rhodes, C. \& BerG, P. (1977). Labelling deoxyribonucleic acid to high specific activity in vitro by nick translation with DNA polymerase I. Journal of Molecular Biology 113, 237-251.

SelveraJ, G. \& IYeR, V. N. (1984). Transposon Tn5 specifies streptomycin resistance in Rhizobium spp. Journal of Bacteriology 158, 580-589.

Simon, R., Priefer, U. \& Puhler, A. (1983). A broad host range mobilization system for in vivo genetic engineering: transposon mutagenesis in Gram negative bacteria. Bio/Technology 1, 784-789.

TAYLOR, J. D. (1972a). Specificity of bacteriophages and antiserum for Pseudomonas pisi. New Zealand Journal of Agricultural Research 15, 421-431.

TAYLOR, J. D. (1972b). Races of Pseudomonas pisi and sources of resistance in field and garden peas. New Zealand Journal of Agricultural Research 15, 441-447.

TAYLOR, J. D. (1986). Bacterial blight of compounding peas. In 1986 British Crop Protection Conference Pests and Diseases, vol. 2, pp. 733-736. Brighton, UK: BCPC.

TAYLOR, J. D. \& DYE, D. W. (1972). A survey of the organisms associated with bacterial blight of peas. New Zealand Journal of Agricultural Research 15, 432-440.

TOWNER, K. J. \& Vivian, A. (1976). RP4 fertility variants in Acinetobacter calcoaceticus. Genetical Research 28, 301-306.

Turner, P., Barber, C. \& Daniels, M. (1984). Behaviour of the transposons $\operatorname{Tn} 5$ and $\operatorname{Tn} 7$ in Xanthomonas campestris pv. campestris. Molecular and General Genetics 195, 101-107.

WATSON, M. D. \& SCAIFE, J. G. (1980). Integrative compatibility: stable coexistence of chromosomally integrated and autonomous derivatives of plasmid RP4. Journal of Bacteriology 142, 462-466. 